\title{
Geographic Labor Mobility of Floating Migrant Workers in China: The Impacts of Health Status and Education on Earnings
}

\author{
Chien-Ping Chen ${ }^{1}{ }^{*}$, Lin Guo², Lijian Qin ${ }^{3}$ \\ ${ }^{1}$ School of Business Administration, University of Houston-Victoria, Katy, USA \\ ${ }^{2}$ Department of Sociology, Huazhong University of Science and Technology, Wuhan, China \\ ${ }^{3}$ Finance and Public Administrative School, Anhui University of Finance and Economics, Bengbu, China \\ Email: *chenc@uhv.edu,guolinruc@163.com, qinlijian28@163.com
}

How to cite this paper: Chen, C.-P., Guo, L. and Qin, L.J. (2018) Geographic Labor Mobility of Floating Migrant Workers in China: The Impacts of Health Status and Education on Earnings. Theoretical Economics Letters, 8, 2345-2362.

https://doi.org/10.4236/tel.2018.811152

Received: March 22, 2018

Accepted: August 12, 2018

Published: August 15, 2018

Copyright (c) 2018 by authors and Scientific Research Publishing Inc.

This work is licensed under the Creative

Commons Attribution International

License (CC BY 4.0).

http://creativecommons.org/licenses/by/4.0/

\begin{abstract}
The geographic labor mobility has been ignored in the studies related to the impacts of health status or education on floating migrant workers' earnings in China. Based on a dataset collected by the World Bank collaborated with the Chinese Academy of Social Sciences in 2010, we initiate the assessment of geographic mobility and explore the indirect impacts from health, education, and other factors on earnings through it. A relatively poor, single, educated migrant in good health with parent at home working in the manufacturing sector presents the strongest geographic mobility. The comparative results indicate that the total health impacts on earnings are generally underestimated for migrant workers at poor or fair health status and the education advancement has a greater impact on earnings for the majority of migrant workers who exhibit the "healthy migrant effect". Our findings not only justify the ground of mixed results in the previous studies but also provide policy making implications. Given the concave relationship between health status and geographic labor mobility, the ongoing health care reform in China should provide local affordable services to attract returning migrants and enhance their earnings.
\end{abstract}

\section{Keywords}

Labor Mobility, Migrant Workers, Health Status, Education,

Earnings, China

\section{Introduction}

Migrant workers have been making essential contribution to the China's econ- 
omy. According to the 2016 report of National Bureau of Statistics of China, more than 280 million internal migrant workers mainly engaged in transportation, commerce, catering, urban environment cleaning and construction work, have contributed at least $16 \%$ of China's gross domestic product (GDP) over the past 20 years. Given the stringent household registration (hukou) system in China, the majority of migrant workers are defined as "floating", apart from their domicile and working in either the other provinces (i.e. 159 million) or within home provinces (i.e. 94 million) more than 6 months without official and affordable access to public education and social welfare programs [1]. They typically leave children behind and shoulder higher health care costs (i.e. either higher insurance premiums or extra travelling costs back for residence health care) at working destination. Poor living quality, high occupational risks, and insufficient local health care have raised the concerns of their health status. Since 2010, county governments have been encouraging return migration by providing more local business opportunities associated with more affordable health care and education advancement. As Chen and Hamori [2] pointed out, how to improve their living and stabilize domestic labor supply has become one of the most important issues in China.

Interestingly, the floating migrants in China have the best self-rated health and report the least acute illness, chronic disease, and disability, after controlling for age and education [3]. The so-called "healthy migrant effect", initiated by Fennelly [4] to highlight the self-selection of healthier rural residents facilitating the migration decision, has been confirmed by numerous empirical studies in different countries [5] [6] [7] [8] [9]. In China, many surveys of rural residents also generally confirmed that a better health status facilitates their internal migration decision [10] [11]. In good health, young and better-educated male rural individuals are more likely to migrate [12]. However, the studies for the health impacts on floating migrants' earnings (i.e. non-farm income) in China have shown mixed results. For example, Zheng et al. [13], Fu and Wang [14], and Qin et al. [15] validated the positive impact of better health status on income through a higher productivity or longer working hours. On the other hand, Cao and $\mathrm{Du}$ [16] and Tian [17] concluded that a good health status has neither economic nor statistical influence on their income or earnings. Furthermore, Gong et al. [18] and Qing and Zheng [19] argued that a longer working time associated good health has an ultimate negative impact on the earnings for migrant workers due to long-term health damage. Those mixed empirical results may come from either varied samples of different provinces or the methodology in which health status is simply considered as a direct impact on migrant workers' earnings. Similar to health status, another important factor for migrant workers' income determination, the education, has been also considered as a direct impact and confirmed by previous studies [20] to be positively related to health and income. However, there is a lack of marginal impact comparison between health status and education for migrant workers in China. The ignorance of possible indirect 
impacts through an intermediate factor such as geographic mobility may lead the policy makers to misestimate the total impacts of health and education on floating migrant workers' earnings.

The present study explores the total impacts of health status and education on floating migrant workers' earnings by considering geographic labor mobility as an intermediate factor in income determination. The rationale is simple; a healthier and more educated rural individual is not only more likely to make migration decision but also more capable to travel further for better job opportunities in a distanced destination working site. The geographic labor mobility, affected by health status, education, and the other demographic factors, is supposed to play an important role to determine a migrant worker's earnings. The total impacts from better health status on earnings are constructed directly by higher productivity or longer working hours, and facilitated indirectly by the geographic mobility. Therefore, we try to answer the following three questions: 1) what are the factors to determine a migrant worker's geographic mobility? If both health status and education are the significant determinants, then 2) how do they affect earnings through geographic mobility indirectly? Finally, 3) compared with education and the other demographic factors such as land holding, whether the total impacts of health status play a more important role in earnings determination? Our analysis will clarify the ground for mixed results in previous studies and provide policy makers the more effective resource allocation between health status improvement and education advancement to enhance floating migrant workers' earnings. Which industry sectors are more strongly related to geographic mobility will be also explored.

We analyze the 2010 survey conducted by the World Bank collaborated with the Chinese Academy of Social Sciences for Sichuan, the largest province in terms of population and labor export, to initiate an assessment of the geographic labor mobility for floating migrant workers. Applying the two-stage least square (2SLS) analysis to solve possible endogeneity problem, we construct the earnings estimation to verify the direct and indirect impacts of health status, education, and the other demographic factors. We found that a poor (i.e. with a relatively small land holding), single, and educated migrant in good but not excellent health status with parent at home working in the manufacturing sector exhibits the strongest geographic mobility. The geographic mobility is also one of the most important and significant determinants of earnings. The total health impacts on earnings are generally underestimated for migrant workers at poor or fair health status and the education advancement exhibits a greater impact on earnings for those who at good or excellent health status. For a more efficient resource allocation to improve their earnings, the government should focus on the unhealthy migrants to offer affordable health care and provide education advancement for the healthier migrant workers.

The remaining sections of this paper are organized as follows. The next section reviews the existing literatures related to health status and geographic labor 
mobility. The data source and the descriptive statistics of key variables follow. The two-stage regression model, the results of empirical analysis, and a simulation for marginal impact comparison between health status and education are illustrated and discussed. The final section concludes and provides policy implications for the ongoing health reform in China.

\section{Literature Review}

Since health is viewed as a durable capital stock for production in Grossman [21], numerous studies for developed countries have confirmed that health status is positively related to labor income through prolonged participation [22] [23] [24] [25] [26] and improved productivity [27] [28] [29] [30]. For developing countries, the impacts of health status on labor income differ in countries associated with the other demographic factors such as gender and education. For example, Thomas et al. [31] conduct an Indonesian interference experiment to indicate the health impact only exists among male labors; Thomas and Strauss [28] investigate Brazilian workers and find that a better health status only raises the salary for less-educated male workers. For migrant workers in China, Jiang and Zhang [32] indicate that poor health status only weakens labor participation for female migrant workers. $\mathrm{Wu}$ [12] and Liang and Tokunaga [33] indicate that healthy and more educated tend to migrate for higher income but Yang and Tokunaga [34] confirm that less-educated rural residents tend to tend to do so. Those mixed results associated with gender and education may also come from the ignorance of an important intermediate factor, geographic labor mobility.

The existing literatures addressing geographic labor mobility (i.e. distance travelled) for internal migrant workers are relatively limited. Both Nicholas and Shergold [35] and Boyer [36], examining the $19^{\text {th }}$ century migrant workers in Australia and England respectively, conclude that long distance migration depended on wage differentials, job opportunities and job-search costs. Lucas [37] analyzes a substantial of migration studies for both industrialized and developing economies to indicate that geographic poverty traps deter distant migration. Windzio [38] analyzes the mobility rate in Germany to conclude that distance hurts mobility but its negative impact is counteracted by a higher level of education. Vakulenko et al. [39] investigate Russian internal migrant workers to find that social and economic factors only affect nearby migration. If the distance between origination and destination is greater than $500 \mathrm{~km}$, then all the factors become uncorrelated. Magrni et al. [40] inspect young French workers to conclude that the wage returns to migration distance are positive only for lesseducated workers. Although the relationship among distance, wage and education are explored with mixed results in those studies, the role of health status in migration distance determination is still groundless.

Numerous studies have discussed the restricted labor mobility caused by the household registration (hukou) system in China. However, they mainly focus on the probability of migration decision [41] [42] [43], the job and sector mobility 
[44] [45], or the expected economic improvement after easing hukou [46] [47]. The geographic labor mobility for floating migrant workers did not get enough attention. There are only some studies related to destination distance and originating provinces. For example, Zhang and Song [48] separate inter-province and intra-province migrant workers to conclude that the former were encouraged by rural-urban income gap and discouraged by geographic distances to destinations; and the later were not affected by geographic distances at all. Liang and Tokunaga [33] find short distance plays a vital role in attracting floating migration in the north but not an important factor for migrants to the southeast coastal areas. Wang [49] indicates that the land holding has a U-shaped curve associated with the probability of short-distant migration but an inverted-U-shaped curve with long-distance migration; that is, either small-land holders or large-land holders tend to migrate in short-distance but the relationship reverses for long distance. Han and Liu [50] point out that the health impact on income is more significantly for migrant workers originated from West China compared with those from the East. All the previous studies just confirm the conventional wisdom in which the poor inland-rural residents tend to migrate further to the metropolitian area in coastal provinces. There is still no assessment for the geographic labor mobility which is determined by health status, land holding, education, and other demographic factors for Chinese floating migrant workers.

\section{Data and Descriptive Statistics}

The data used in this study are from the survey conducted by the World Bank collaborated with the Chinese Academy of Social Sciences. The face-to-face survey, conducted by trained interviewers, was implemented in Sichuan Province of China in late December 2010. Sichuan, the largest inland province in terms of population and labor export, serves as the best representative province for floating migrant workers. A four-step Probability Proportionate to Size (PPS) sampling method was piloted as the following. The first step, 3 counties were selected randomly from 10 counties in Sichuan Province. Then 3 towns within each chosen county were selected. Similarly, the third step chose 3 villages randomly from each county. Finally, 50 households were drawn from each village. There were a total 1314 households and 4758 individuals conducted in the survey. To focus on floating migrant workers on the behalf of studying scope, our sample keeps individuals who have been working full time outside their domicile for at least 30 days already andaged from 16 to 65 . We also eliminate those who already changed registered residence (i.e. hukou) to working destination. Finally, we obtain 1385 floating migrant workers as the sample size.

For the convenience in marginal impact comparison, we apply the four-category scale to define the proxy for geographic mobility, health status, and education. To measure geographic mobility, we classify the self-reported working destination as 1 (within town), 2 (within county), 3 (within province), and 4 (outside province). Although one category may contain varied migration distances, the 
possible financial burdens associated with limited healthcare access and transportation costs are supposed to be similar within the same scale. For health status, in accord with previous studies [23] [28] [51], we adopt the self-reported status scale into 1 (poor), 2 (fair), 3 (good) and 4 (excellent). Any possible bias from healthy migrant effect is ignored here for simplification. For education, we also ascend illiterate/primary school to college education from 1 to 4 as the proxy. Table 1 summarizes the descriptive statistics of annual earnings (i.e. non-farm income) associated with the four categories for each variable.

Table 1 indicates that a migrant worker's average earnings increase in each of the three variables: geographic mobility, health status, and education. Given the mean of annual earnings at 13,380 RMB, migrant workers choosing a nearby town as destination are making $12.6 \%$ less than the average; in contrast, those who working outside-province are make $17.6 \%$ more than the average. There exists an obvious trend of increasing earnings for migrants working in a further destination. Here we have to note that the percentage of outside-province workers in our sample, about $10 \%$, is much less than the average percentage of mid-west provinces, about $60 \%$ according to National Bureau of Statistics of China [1]. Due to the timing of survey was in late December, it is not surprisingly that most floating migrant workers who work outside province were not back to home valley yet. They generally wait until the Chinese Lunar New Year coming in early February then travel back for family reunion. However, the less

Table 1. Descriptive statistics of categories in key variables.

\begin{tabular}{|c|c|c|c|c|}
\hline Variables & Frequency & Percentage & \multicolumn{2}{|c|}{ Annual Earnings (RMB) } \\
\hline & & & Mean & Std. Dev. \\
\hline \multicolumn{5}{|l|}{ Mobility } \\
\hline Within town & 675 & 48.74 & $12,085.45$ & 9887.69 \\
\hline Within county & 189 & 13.65 & $15,096.59$ & $12,323.22$ \\
\hline Within province & 384 & 27.73 & $15,407.29$ & $11,787.08$ \\
\hline Outside province & 137 & 9.89 & $16,261.31$ & 9342.66 \\
\hline \multicolumn{5}{|l|}{ Health Status } \\
\hline Poor & 68 & 4.91 & 8394.26 & 6911.54 \\
\hline Fair & 289 & 20.87 & $12,344.74$ & 9388.33 \\
\hline Good & 451 & 32.56 & $14,148.48$ & $10,911.17$ \\
\hline Excellent & 577 & 41.66 & $14,966.60$ & $11,640.82$ \\
\hline \multicolumn{5}{|l|}{ Education } \\
\hline Illiterate/Primary school & 407 & 29.39 & $11,199.02$ & 9715.50 \\
\hline Middle school & 733 & 52.92 & $14,195.96$ & $11,056.37$ \\
\hline High school & 199 & 14.37 & $16,689.95$ & $11,213.89$ \\
\hline College & 46 & 3.32 & $18,917.39$ & $10,763.05$ \\
\hline Total & 1385 & 100 & $13,830.42$ & $10,874.02$ \\
\hline
\end{tabular}


participation of outside-province workers in the survey will not affect our analysis in the next section. The sample size is still large enough to reach unbiased results.

For health status, more than $74 \%$ of migrant workers rate themselves at good or excellent level to echo the possible healthy migrant effect. The most healthy one is making $78.3 \%$ more than the one with poor health. However, the gap in earnings from a better health status declines gradually. For education, only about $18 \%$ of migrant workers have a high school diploma or above. A college degree holder, a little bit more than 3\% among all migrant workers, is making 36.8\% more than the average. We have to note that college graduates from valleys are more likely to migrate permanently by giving up their rural domicile. They are not considered as floating migrants in our sample. Similar to health status, the income gap from a higher education also declines gradually. When both health status and education are considered as the two main factors to determine a floating migrant worker's earnings in all the previous studies, we will compare their total impacts on earnings directly and indirectly through the geographic mobility in the next section. The other demographic factors, such as gender, age, marriage status, parent at home or not, acre of farm land, scale of saving deposit, and house value, will also construct the assessment of geographic labor mobility. Their descriptive statistics are summarized in Table 2.

\section{Econometric Models and Empirical Results}

\subsection{Geographic Labor Mobility}

We initiate a pioneer assessment of geographic labor mobility for floating migrant workers in China. Unlike the new economic geography (NEG) models examining the cognitive processes underlying spatial arrangement or reasoning [47] [52], our model seeks the significant determinants considered in previous studies for migrant workers to travel further. In addition to the demographic factors summarized in Table 2, we also verify the impacts from health status $(H)$, acres of land holding $(A)$, education $(E)$ and industry choice $(I)$ on geographic mobility. Based upon the possible non-linear relationship of health

Table 2. Summary of descriptive statistics for the other demographic factors.

\begin{tabular}{|c|c|c|c|c|}
\hline Variables & Mean & Std. Dev. & Minimum & Maximum \\
\hline Gender $($ male $=1$ and female $=0)$ & 0.6058 & 0.4889 & 0 & 1 \\
\hline Age & 39.8830 & 11.2112 & 16 & 65 \\
\hline $\begin{array}{c}\text { Marriage Status } \\
(\text { married }=1, \text { otherwise }=0)\end{array}$ & 0.8404 & 0.3663 & 0 & 1 \\
\hline $\begin{array}{l}\text { At least one Parent at home } \\
\qquad(\text { yes }=1, \text { no }=0)\end{array}$ & 0.4137 & 0.4927 & 0 & 1 \\
\hline Acre of farm land & 2.9221 & 2.9026 & 0 & 50 \\
\hline Scale of Saving Deposit & 2.1061 & 1.4434 & 1 & 5 \\
\hline Value of house in household & 150,474 & 221,425 & 0 & $2,750,000$ \\
\hline
\end{tabular}


status and geographic mobility and the confirmed non-linear relationship between land holding and probability of migration decision found in Wang [49], we construct a curvilinear model for health status and land holding as a better-fit model. The ordered log it model of geographic mobility, $M_{i}$, for a migrant worker $i$ is constructed as the following:

$$
M_{i}=\alpha_{1} H_{i}+\alpha_{2} H_{i}^{2}+\alpha_{3} A_{i}+\alpha_{4} A_{i}^{2}+\alpha_{5} E_{i}+\alpha_{6 j} \Pi_{i j}+\alpha_{7} I_{i k}+\varepsilon_{i},
$$

in which $\Pi_{j}$ denotes the matrix of $j$ demographic factors; $I_{k}$ denotes the varied industry $k$ sectors (referenced to construction), including manufacturing, restaurant/hotel, transportation, residential service, retail and the other; $\varepsilon_{i}$ is random error. The purpose to consider the industry choice in geographic mobility is to validate which sectors attract more labor forces from inland provinces to travel further for job opportunities.

The possibility of endogeneity and causality problems is quite limited here. First, sufficient independent variables are considered in the model. The probability of missing explanatory variable related to the residual term is minimized. Second, we use the cross-sectional data, not the dynamic panel data with lag of dependent variable, to avoid the auto-correlation problem. Third, the so-called "healthy migrant effect" in numerous studies already confirmed the causality between geographic mobility and health status. Although some causality testing can be only done by time-series data such as the test in Granger [53], Mariusz [54] argues that the causal relationship among cross-sectional variables can be still confirmed without the possible fallacy when the true relationship involves three or more variables in panel data.

The results in Table 3 indicate several interesting findings related to a floating migrant worker's geographic mobility. First, both health status and acres of land holding exhibit a very significant concave relationship (i.e. at $1 \%$ level of significance) with the geographic mobility. The first order and second order derivatives from Equation (1) are shown in the following:

$$
\begin{aligned}
& \frac{\partial M}{\partial H}=1.0136-0.3710 H \geq 0, \text { when } H \leq 2.732 ; \frac{\partial^{2} M}{\partial H^{2}}<0 ; \\
& \frac{\partial M}{\partial A}=0.2743-0.0320 A \geq 0, \text { when } A \leq 8.571 ; \frac{\partial^{2} M}{\partial A^{2}}<0 .
\end{aligned}
$$

Based upon the health status proxy as the scale of 1 (poor), 2 (fair), 3 (good) and 4 (excellent), the results imply that an improved health status will boost migrant workers' geographic mobility only for those who rate their status as poor or fair. The marginal impact of health on geographic mobility also declines gradually. At a good or excellent status, a healthy migrant worker's mobility cannot be enhanced by incremental health improvement. This concave relationship between health status and geographic mobility may explain the mixed results of health impact on earnings found in previous studies.

The similar concave relationship of land holding implies that the geographic mobility starts to decline when a migrant worker's household owning more than 
Table 3. Ordered log it model of geographic labor mobility.

\begin{tabular}{|c|c|c|}
\hline Variable & Coefficient & Standard Error \\
\hline Health status & $1.0136^{\star * \star}$ & 0.3886 \\
\hline Health status-square & $-0.1855^{* * *}$ & 0.0674 \\
\hline Acres of farm land & $0.2743^{* * *}$ & 0.0412 \\
\hline Acres of farm land-square & $-0.0160^{* * *}$ & 0.0037 \\
\hline Education & $0.1397^{\star}$ & 0.0803 \\
\hline Gender $($ male $=1$ and female $=0)$ & 0.1152 & 0.1167 \\
\hline Age & -0.0079 & 0.0076 \\
\hline Marriage status $($ married $=1$, otherwise $=0$ ) & $-0.8014^{* * *}$ & 0.1536 \\
\hline At least one parent at home $($ yes $=1$, no $=0$ ) & $0.5162^{* * *}$ & 0.1556 \\
\hline Scale of saving deposit & $-0.0910^{* *}$ & 0.0394 \\
\hline Log value of house in household & $-0.0667^{* * *}$ & 0.0154 \\
\hline \multicolumn{3}{|l|}{ Industry (Referenced: Construction ) } \\
\hline Manufacturing & $0.4017^{* * *}$ & 0.1566 \\
\hline Restaurant/Hotel & $-0.5483^{* *}$ & 0.2350 \\
\hline Transportation & -0.0803 & 0.2175 \\
\hline Residential Service & $-0.6346^{* * *}$ & 0.1705 \\
\hline Retail & $-0.5133^{\star * *}$ & 0.2004 \\
\hline Other & $-0.3866^{*}$ & 0.2283 \\
\hline
\end{tabular}

Note: ${ }^{* *},{ }^{* *}$ and ${ }^{*}$, denote significance at 1,5 and 10-percent level, respectively. $\mathrm{R}^{2}=0.0965$.

8.571 acres of farmland. The result echoes the finding in Wang [49] that the probability of long-distance migration decision is restrained by a larger scale of farmland holding. Owning a larger farmland, a migrant might come back more frequently to take care of farm production activities. As a result, they tend not to choose a distanced working destination. Their earnings (i.e. non-farm income) may be also limited due to the large farm land holding.

Second, education and the other demographic factors exhibit varied impacts on geographic mobility. As expected, more education will expand geographic labor mobility (i.e. at a $10 \%$ level of significance). Educated migrant workers tend to have a stronger confidence to work at a further destination. However, the rationale to maintain their rural hukou may come from the expected benefit or compensation related to government's future land reform policy which is outside the studying scope of this paper. Interestingly, although some empirical studies [12] have confirmed that male and young rural residents are more likely to make migration decision, neither gender nor age exhibits significant impacts on geographic mobility in our case. It implies that once the migration decision is made, the distance of destination will not be influenced by gender and age. On the other hand, marriage status and parental help affect geographic mobility significantly. With family burden, a married migrant worker cannot to travel fur- 
ther unless there is at least one parent at home providing child care which is relatively costly in working destination [55] [56]. To a single migrant worker, parental help in caring farm activities of assigned land acreage will also expand his or her geographic mobility. Not surprisingly, both saving deposit and house value have a significantly negative impact on geographic mobility. Combined with the nonlinear impacts of land holding, a wealthier migrant worker is less likely to choose a destination far away from home village.

For industry sectors, the significant coefficients indicate that floating migrant workers tend to travel further to fulfill the job opportunities in the manufacturing sector only. It is an expected result given that most manufacturing jobs are available in coastal provinces and most floating migrants originate from inland provinces in China. The more interesting result is that all the service sectors, including restaurant/hotel, residential service and retail, exhibit a significantly negative relationship with geographic labor mobility. It implies that floating migrants tend to work in those sectors in a shorter-distance destination from home valley. The outcome might come from a less income gap between those sectors and farming or simply result from the employers' preference over same-province laborers. Although it is outside the studying scope of this paper, the possible favoritism of same county/province employees in the service sectors is worth to be explored in future studies. In summary, a relatively poor, educated, single migrant at good health status with parental help at home valley, exhibits the stronger geographic mobility to work in the manufacturing sector. We believe that the geographic mobility is one of the most important determinants for a migrant worker's earnings in China.

\subsection{Income Estimation for Floating Migrant Workers}

To explore the direct and indirect impacts of health status and the other factors on a floating migrant worker's earnings (i.e. non-farm income) through geographic mobility, we apply a two-stage least square (2SLS) analysis to construct the earnings estimation for a migrant worker $i$ as the following log-linear model:

$$
\ln Y_{i}=\beta_{0}+\beta_{1} \ln M_{i}+\beta_{2} \ln H_{i}+\beta_{3} \ln A_{i}+\beta_{4} \ln E_{i}+\beta_{5 j} \Pi_{i j}+\beta_{6} I_{i k}+{ }_{i} .
$$

In Equation (2), $Y$ is the annual earnings; all the rest of variables are similar to those in Equation (1), except the demographic vector $\Pi_{j}$ which contains only gender, age and marriage status which are the common factors in previous studies related to income estimation.

Table 4 shows several interesting results for floating migrant workers' earnings in China. First, all the geographic mobility, health status, land holding, and education have direct and significant impacts (i.e. at $1 \%$ level of significance) on earnings. Compared with the other factors, the health status plays a much more important role in the direct determination of earnings. At one percent incremental change, the health status improvement contributes a $0.4181 \%$ of increase in earnings, compared with $0.2906 \%$ from mobility and $0.2737 \%$ from education. In contrast, one percent incremental land holding reduces a slight $0.1318 \%$ 
Table 4. Log-linear OLS estimation for floating migrants' earnings.

\begin{tabular}{ccc}
\hline Variable & Coefficient & Standard Error \\
\hline Ln Mobility & $0.2906^{* * *}$ & 0.0410 \\
Ln Health Status & $0.4181^{* * *}$ & 0.0855 \\
Ln Acres of Farm Land & $-0.1318^{* * *}$ & 0.0289 \\
Ln Education & $0.2737^{* * *}$ & 0.0580 \\
& & \\
Gender (male = 1 and female =0) & $0.2268^{* * *}$ & 0.0448 \\
Age & $-0.0097^{* * *}$ & 0.0024 \\
Marriage Status (married = 1, otherwise $=0)$ & $0.2734^{* * *}$ & 0.0628 \\
Industry (Referenced: Construction ) & & \\
Manufacturing & 0.0875 & 0.0615 \\
Restaurant/Hotel & 0.0285 & 0.0914 \\
Transportation & $0.1969^{* *}$ & 0.0888 \\
Residential Service & -0.0841 & 0.0652 \\
Retail & $0.1837^{* *}$ & 0.0772 \\
Other & -0.1270 & 0.0890 \\
Constant & $8.4952^{* * *}$ & 0.1836 \\
\hline
\end{tabular}

Note: ${ }^{* * *},{ }^{* *}$ and ${ }^{*}$, denote significance at 1,5 and 10 -percent level, respectively; $\mathrm{R}^{2}=0.1601$.

of non-farm income as expected. Second, the coefficients of demographic factors imply that a married, young, and male floating migrant worker is making a greater non-farm income significantly. However, working in the manufacturing sector does not earn more significantly; instead, only transportation and retail sectors exhibit advantages in earnings. The transportation sector might benefit from the increasing governmental investment in infrastructure right after the global financial crisis in 2008 to boost the economy; the retail business might also take off after China transited from a developing country to an emerging economy in the late 2000s.

To solve the possible endogeneity problem and explore the indirect impacts through geographic labor mobility on income, we apply the two-stage least square (2SLS) method here; that is, plugging Equation (1) into Equation (2). The total impacts from health status, land holding and education on earnings may become either stronger or weaker than their direct impacts. Their first derivatives are shown in the Appendix. The mixed results of impacts on earnings in previous empirical studies, especially in the field of health, may be explained through the non-linear relationships related to geographic mobility. For comparison, we proceed a simple simulation to illustrate the total marginal impacts of health status and education on earnings for a representative floating migrant worker, a single male who is working in the manufacturing sector with at least one parent at home and average values of the other demographic factors: 
Table 5 exhibits the total marginal impacts on earnings in which $\hat{H}=\frac{\partial \ln Y}{\partial \ln H}$ denotes that from health status and $\hat{E}=\frac{\partial \ln Y}{\partial \ln E}$ from education. As derived in the Appendix, the total impacts of health status on earnings are much less than the direct impact (i.e. 0.4181) for a migrant worker self-rated at good or excellent level. In contrast, for those who at poor or fair health status, the total impacts on earnings are greater than the direct impacts. When the health migrant effect in China is reaffirmed by Hesketh et al. [3], our analysis validates that the mixed results of health impact on earnings in previous studies may easily come from the ignorance of geographic mobility. On the other hand, education can be an underestimated factor in earnings determination. Its total impacts are not only greater than the direct impact (i.e. 0.2737) at all levels but decline initially then increase gradually in health status improvement. To an average male single migrant worker in the manufacturing sector, one percent improvement in health status will contribute more in earnings compared with that in education for those who rate themselves at poor or fair health status. The positive contribution from health improvement in earnings also declines in education advancement. For a migrant worker at excellent health status, the marginal impacts from advanced education on earnings is at least twice as that from health improvement. When the government has limited budget to boost their earnings by either improved health or advanced education, our results provide the trade-off criteria for efficient resource allocation.

\section{Concluding Remarks}

The impact of geographic labor mobility on earnings for floating migrant workers in China has been ignored for decades. While the total relaxation of household registration (hukou) system is still in the air, the governmental intervention on health reform or education advancement is required to improve those workers' living. This study initiates a framework to measure geographic mobility and assess the total impacts of health status and education on earnings through it. We found that the total health impacts are generally underestimated for migrant workers at poor or fair health status and the education advancement has a greater impact on earnings for the migrant workers who exhibit the "healthy migrant

Table 5. Marginal impacts of health status and education on earnings.

\begin{tabular}{cccccccccc}
\hline & \multicolumn{10}{c}{ Education } \\
\hline \multirow{2}{*}{ Health Status } & \multicolumn{1}{c}{ Illiterate/Primary } & \multicolumn{1}{c}{ Middle School } & \multicolumn{2}{c}{ High School } & \multicolumn{2}{c}{ College } \\
\cline { 2 - 11 } & $\hat{H}$ & $\hat{E}$ & $\hat{H}$ & $\hat{E}$ & $\hat{H}$ & $\hat{E}$ & $\hat{H}$ & $\hat{E}$ \\
\hline Poor & 0.5550 & 0.3034 & 0.5422 & 0.3276 & 0.5317 & 0.3478 & 0.5228 & 0.3647 \\
Fair & 0.5047 & 0.2959 & 0.4986 & 0.3151 & 0.4932 & 0.3316 & 0.4885 & 0.3461 \\
Good & 0.3726 & 0.2949 & 0.3757 & 0.3133 & 0.3784 & 0.3294 & 0.3808 & 0.3435 \\
Excellent & 0.0810 & 0.2987 & 0.1077 & 0.3197 & 0.1305 & 0.3377 & 0.1502 & 0.3532 \\
\hline
\end{tabular}


effect". In addition, our analysis also verifies the concave relationship between land holding and geographic mobility to confirm the non-linear impacts of land holding on earnings which echoes the finding in Wang [49]. With more acres of farm land, a migrant worker's geographic mobility eventually declines and his or her non-farm income also falls. Finally, only the floating migrant workers in manufacturing sector exhibit a significantly stronger geographic labor mobility. In the other service sectors, they tend to find a closer destination.

The findings of this study have several important policy implications. First, when the majority of migrant workers exhibit the "healthy migrant effect", the more effective policy to improve their earnings significantly is education advancement. The health improvement has a much greater impact on earnings only for those rating at poor or fair health status. For an efficient resource allocation to enhance earnings, more affordable health care should be provided to the unhealthy and better educational opportunities should be offered to the healthy. In addition, due to the concave relationship between health and geographic mobility, the local government may attract more returning migrant workers by providing better health care. Second, land holding is also an important factor to influence both geographic mobility and earnings for floating migrants. Any improvement to inspire a rural resident's geographic mobility or earnings will have a more significant outcome for those who with a relatively smaller land holding. Third, although the floating migrants working in the manufacturing sector exhibit a stronger geographic mobility, their earnings are not greater than those who in the other sectors. Policy makers should target them as returning migrants or provide more remedies to compensate their financial burdens due to long distance away from home valley.

Some limitations exist in this study for sure. Like all health related studies based upon self-rated survey, the possible bias of health migrant effect cannot be eliminated. Although the sample is collected from the largest inland province in terms of population and labor export inland province, it still cannot represent perfectly for the whole migrant worker population in China. A multi-province panel data collection should be done for the future studies. We are also lack of the information about the incremental costs of health improvement and education advancement to proceed cost-benefit analysis for government policy making. For the aspect of industry sectors, the rationales of significantly negative relationship between geographic mobility and service sector are still groundless. Those issues are also supposed to be explored in the future studies.

\section{Conflicts of Interest}

The authors declare no conflicts of interest regarding the publication of this paper.

\section{References}

[1] National Bureau of Statistics of China (2013) Bulletin of Economic and Social De- 
velopment of China.

http://www.stats.gov.cn/english/pressrelease/201402/t20140224_515103.html

[2] Chen, G. and Hamori, S. (2009) Solution to the Dilemma of the Migrant Labor Shortage and the Rural Labor Surplus in China. China and World Economy, 17, 53-71. https://doi.org/10.1111/j.1749-124X.2009.01158.x

[3] Hesketh, T., Jun, Y., Lu, L. and Mei, W. (2008) Health Status and Access to Health Care of Migrant Workers in China. Public Health Reports, 123, 189-197. https://doi.org/10.1177/003335490812300211

[4] Fennelly, K. (2007) The "Healthy Migrant" Effect. Minnesota Medicine, 90, 51-53.

[5] Razum, O., Zeeb, H. and Rohrmann, S. (2000) The "Healthy Migrant Effect"-Not Merely a Fallacy of Inaccurate Denominator Figures. International Journal of Epidemiology, 29, 191-192. https://doi.org/10.1093/ije/29.1.191

[6] Kennedy, S., McDonald, J. and Biddle, N. (2006) The Healthy Immigrant Effect and Immigrant Selection: Evidence from Four Countries. Social and Economic Dimensions of an Aging Population Research Papers No. 164.

[7] Chiswick, B., Lee, Y. and Miller, P. (2008) Immigrant Selection Systems and Immigrant Health. Contemporary Economic Policy, 26, 555-578. https://doi.org/10.1111/j.1465-7287.2008.00099.x

[8] Mehta, N. and Elo, I. (2012) Migrant Selection and the Health of U.S. Immigrants from the Former Soviet Union. Demography, 49, 425-447. https://doi.org/10.1007/s13524-012-0099-7

[9] Nauman, E., VanLandingham, M., Anglewicz, P., Patthavanit, U. and Punpuing, S. (2015) Rural-to-Urban Migration and Changes in Health among Young Adults in Thailand. Demography, 52, 233-257. https://doi.org/10.1007/s13524-014-0365-y

[10] Knight, J., Deng, Q. and Li, S. (2011) The Puzzle of Migrant Labour Shortage and Rural Labour Surplus in China. China Economic Review, 22, 585-600. https://doi.org/10.1016/j.chieco.2011.01.006

[11] Zou, F. and Fang, F. (2013) Health Shock, Health Investment and Vulnerability of Poverty: Evidence from CHNS. Social Science Research, 34, 1-7 (in Chinese).

[12] Wu, Z. (2010) Self-Selection and Earnings of Migrants: Evidence from Rural China. Asian Economic Journal, 24, 23-44. https://doi.org/10.1111/j.1467-8381.2010.02028.x

[13] Zheng, S., Wang, Z., Wang, H. and Song, S. (2010) Do Nutrition and Health Affect Migrant Workers' Income? Some Evidence from Beijing, China. China \& World Economy, 18, 105-124. https://doi.org/10.1111/j.1749-124X.2010.01215.x

[14] Fu, L. and Wang, C. (2014) Study on the Impact of Human Capital on the Income in China. China Collective Economy, 29, 65-67 (in Chinese).

[15] Qin, L., Chen, C., Liu, X., Wang, C. and Jiang, Z. (2015) Health Status and Earnings of Migrant Workers from Rural China. China \& World Economy, 23, 84-99. https://doi.org/10.1111/cwe.12108

[16] Cao, G. and Du, W. (2011) Health Influence upon Employment and Income. Inquiry into Economic Issues, 21, 134-138.

[17] Tian, Y. (2013) Research on the Correlation between Health and Wage by Simultaneous Equations. South China Population, 28, 19-27. (In Chinese)

[18] Gong, B., Guo, D. and Tang, Y. (2010) Determinants on Off-Farm Income of the Migrant Workers: Evidence from Hangzhou City Zhejiang Province. Chinese Rural Economy, 26, 87-96. 
[19] Qing, S. and Zheng, J. (2013) The Impact of Discrimination of Position on the Income Gap. China Economic Quarterly, 12, 736-755. (In Chinese)

[20] Huang, R., Fulginiti, L. and Peterson, E. (2010) Health and Growth: Causality through Education. China Agricultural Economic Review, 2, 321-344. https://doi.org/10.1108/17561371011078444

[21] Grossman, M. (1972) On the Concept of Health Capital and the Demand for Health. Journal of Political Economy, 80, 223-255. https://doi.org/10.1086/259880

[22] Smith, J. (1998) Socioeconomics Status and Health. American Economic Review, 88, 192-196.

[23] Pelkowski, J., Messer, J. and Berger, M. (2004) The Impact of Health on Employment, Wages, and Hours Worked over the Life Cycle. Quarterly Review of Economics and Finance, 44, 102-121. https://doi.org/10.1016/j.qref.2003.08.002

[24] Alavinia, S. and Burdorf, A. (2008) Unemployment, Retirement and Ill-Health: A Cross-Sectional Analysis across European Countries. International Archives of Occupational and Environmental Health, 82, 39-45. https://doi.org/10.1007/s00420-008-0304-6

[25] Pilar, G., Jones, A. and Rice, N. (2010) Health Effects on Labor Market Exits and Entries. Labour Economics, 17, 62-76. https://doi.org/10.1016/j.labeco.2009.04.004

[26] Nordstrom, K., Ekberg, K. and Hemmingsson, T. (2014) Sick Leave and the Impact of Job-to-Job Mobility on the Likelihood of Remaining on the Labor Market-A Longitudinal Swedish Register Study. BMC Public Health, 14, 305-318. https://doi.org/10.1186/1471-2458-14-305

[27] Borjas, G.J. (1987) Self-Selection and the Income of Immigrants. American Economic Review, 77, 531-553.

[28] Thomas, D. and Strauss, J. (1998) Health and Wages: Evidence on Men and Women in Urban Brazil. Journal of Econometrics, 77, 159-185. https://doi.org/10.1016/S0304-4076(96)01811-8

[29] Jones, A. and Wildman, J. (2008) Health, Income and Relative Deprivation: Evidence from the BHPS. Journal of Health Economics, 27, 308-324. https://doi.org/10.1016/j.jhealeco.2007.05.007

[30] Fletcher, J., Sindelar, J. and Yamaguchi, S. (2011) Cumulative Effects of Job Characteristics on Health. Health Economics, 20, 553-570. https://doi.org/10.1002/hec.1616

[31] Thomas, D., Frankenberg, E. and Friedman, J. (2006) Causal Effect of Health on Labor Market Outcomes: Experimental Evidence. California Center for Population Research, UCLA Press, Los Angeles.

[32] Jiang, Q. and Zhang, K. (2013) Economics of Beauty in China's Labor Market: Does Structure Matter? China Economic Quarterly, 12, 983-1006. (In Chinese)

[33] Liang, Y. and Tokunaga, S. (2011) Migration and Floating Migration in Hebei Province, China, from Survey Data of Lulong and Changli Counties. Studies in Regional Science, 41, 759-768. https://doi.org/10.2457/srs.41.759

[34] Yang, L. and Tokunaga, S. (2012) Impact of Education and Agricultural Income on Floating Migration in China: A Case Study of Hebei Province. Studies in Regional Science, 42, 423-437. https://doi.org/10.2457/srs.42.423

[35] Nicholas, S. and Shergold, P. (1987) Intercounty Labour Mobility during the Industrial Revolution: Evidence from Australian Transportation Records. Oxford Economic Papers, 39, 624-640. https://doi.org/10.1093/oxfordjournals.oep.a041809

[36] Boyer, G.R. (1997) Labour Migration in Southern and Eastern England, 1861-1901. 
European Review of Economic History, 1, 191-215. https://doi.org/10.1017/S1361491697000099

[37] Lucas, R. (2001) The Effects of Proximity and Transportation on Developing Country Population Migrations. Journal of Economic Geography, 1, 323-339. https://doi.org/10.1093/jeg/1.3.323

[38] Windzio, M. (2004) Between Northern and Southern Germany: Overcoming Spatial Distances in Labour Market Mobility. Journal for Labour Market Research, 37, 29-44.

[39] Vakulenko, E., Mkrtchyan, N. and Furmanov, K. (2011) Econometric Analysis of Internal Migration in Russia. Montenegrin Journal of Economics, 7, 21-33.

[40] Magrini, M. and Lemistre, P. (2013) Distance-Income Migration Trade-Off of Young French Workers: An Analysis per Education Level. Regional Studies, 47, 282-295. https://doi.org/10.1080/00343404.2011.579595

[41] Yang, D. (1997) China's Land Arrangements and Rural Labor Mobility. China Economic Review, 8, 101-115. https://doi.org/10.1016/S1043-951X(97)90001-8

[42] Bao, S., Bodvarsson, O., Hou, J. and Zhao, Y. (2011) The Regulation of Migration in a Transition Economy: China's Hukou System. Contemporary Economic Policy, 29, 564-579. https://doi.org/10.1111/j.1465-7287.2010.00224.x

[43] Song, Y. (2014) What Should Economists Know about the Current Chinese Hukou System? China Economic Review, 29, 200-212. https://doi.org/10.1016/j.chieco.2014.04.012

[44] Zhang, H. (2010) The Hukou System's Constraints on Migrant Workers' Job Mobility in Chinese Cities. China Economic Review, 21, 51-64. https://doi.org/10.1016/j.chieco.2009.10.002

[45] Xu, K. (2014) Barriers to Labor Mobility and International Trade: The Case of China. China Economic Review, 29, 107-125. https://doi.org/10.1016/j.chieco.2014.04.003

[46] Meng, X. (2012) Labor Market Outcomes and Reforms in China. Journal of Economic Perspectives, 26, 75-102. https://doi.org/10.1257/jep.26.4.75

[47] Bosker, M., Brakman, S., Garresten, H. and Schramm, M. (2012) Relaxing Hukou: Increased Labor Mobility and China's Economic Geography. Journal of Urban Economics, 72, 252-266. https://doi.org/10.1016/j.jue.2012.06.002

[48] Zhang, K. andSong, S. (2003) Rural-Urban Migration and Urbanization in China: Evidence from Time-Series and Cross-Section Analyses. China Economic Review, 14, 386-400. https://doi.org/10.1016/j.chieco.2003.09.018

[49] Wang, X. (2013) Different Roles of Land in Rural-Urban Migration: Evidence from China's Household Survey. China and World Economy, 21, 107-126. https://doi.org/10.1111/j.1749-124X.2013.12011.x

[50] Han, M. and. Liu, J. (2013) The Impact of Health Investment Income Growth and Research on Rural-Urban Differences and Regional Differences. Chinese Health Economics, 32, 66-68. (In Chinese)

[51] Noymer, A. and Lee, R. (2013) Immigrant Health around the World: Evidence from the World Values Survey. Journal of Immigrant and Minority Health, 15, 614-623. https://doi.org/10.1007/s10903-012-9637-Z

[52] Hering, L. and Poncet, S. (2010) Income per Capita Inequality in China: The Role of Economic Geography and Spatial interactions. World Economy, 33, 655-679. https://doi.org/10.1111/j.1467-9701.2010.01241.x 
[53] Granger, C.W. (1969) Investigating Causal Relations by Econometric Models and Cross-Spectral Methods. Econometrica, 37, 424-438.

https://doi.org/10.2307/1912791

[54] Mariusz, M. (2015) A Review of Granger-Causality Fallacy. Journal of Philosophical Economics: Reflections on Economic and Social Issues, 8, 86-105.

[55] Giles, J. and Mu, R. (2007) Elderly Parent Health and the Migration Decisions of Adult Children: Evidence from Rural China. Demography, 44, 265-288. https://doi.org/10.1353/dem.2007.0010

[56] Fan, C.C. (2011) Settlement Intention and Split Households: Findings from a Survey of Migrants in Beijing's Urban Villages. China Review, 11, 11-41. 


\section{Appendix}

$$
\begin{gathered}
M_{i}=\alpha_{1} H_{i}+\alpha_{2} H_{i}^{2}+\alpha_{3} A_{i}+\alpha_{4} A_{i}^{2}+\alpha_{5} E_{i}+\alpha_{6 j} \Pi_{i j}+\alpha_{7} I_{i k}+\varepsilon_{i} \\
\ln Y_{i}=\beta_{0}+\beta_{1} \ln M_{i}+\beta_{2} \ln H_{i}+\beta_{3} \ln A_{i}+\beta_{4} \ln E_{i}+\beta_{5 j} \Pi_{i j}+\beta_{6} I_{i l}+\zeta_{i} \\
\frac{\partial \ln Y}{\partial \ln H}=\beta_{1} \frac{\partial \ln M}{\partial \ln H}+\beta_{2}=\beta_{1} \frac{\alpha_{1} H+2 \alpha_{2} H^{2}}{M}+\beta_{2}
\end{gathered}
$$

Given $\beta_{1}>0$ and $M>0$, then $\frac{\partial \ln Y}{\partial \ln H}<\beta_{2}$ if $\alpha_{1} H+2 \alpha_{2} H^{2}<0$.

$$
\frac{\partial \ln Y}{\partial \ln A}=\beta_{1} \frac{\partial \ln M}{\partial \ln A}+\beta_{3}=\beta_{1} \frac{\alpha_{3} A+2 \alpha_{4} A^{2}}{M}+\beta_{3}
$$

Given $\beta_{1}>0$ and $M>0$, then $\frac{\partial \ln Y}{\partial \ln A}<\beta_{3}$ if $\alpha_{3} A+2 \alpha_{4} A^{2}<0$.

$$
\frac{\partial \ln Y}{\partial \ln E}=\beta_{1} \frac{\partial \ln M}{\partial \ln E}+\beta_{4}=\beta_{1} \frac{\alpha_{6} E}{M}+\beta_{4}
$$

Given $\beta_{1}>0, \alpha_{6}>0, \mathrm{E}>0$, and $M>0$, then $\frac{\partial \ln Y}{\partial \ln E}>\beta_{4}$. 